\title{
ATIVIDADE ANTIBACTERIANA DA CASCA DO JUCÁ (Libidibia ferrea (Mart. ex Tul.) L. P. Queiroz), FRENTE A Staphylococcus spp. ISOLADOS DO LEITE DE CABRAS COM MASTITE \\ (antibacterial activity jucá bark (Libidibia ferrea (mart. ex tul.) L. P. Queiroz), against Staphylococcus spp. isolated goats milk with mastitis)
}

\author{
Weslley de Souza Paiva, Francisco Ernesto de Souza Neto, Maria Gilnara Lima Bandeira, \\ Maria Rociene Abrantes, Anabelle Camarotti de Lima Batista, Jean Berg Alves da Silva \\ *Correspondência: wdspaiva@gmail.com:
}

\begin{abstract}
RESUMO: O uso indiscriminado de antibióticos no tratamento de mastite ocasiona a seleção da microbiota resistente, dificultando o tratamento da doença. Esse trabalho teve como objetivo, testar a atividade antimicrobiana do extrato hidroalcoólico da casca de Jucá (Libidibia ferrea (Mart. ex Tul.) L. P. Queiroz) em diferentes concentrações contra micro-organismos causadores de mastite em caprinos. Foram isoladas 18 estirpes bacterianas de cabras com mastite crescidas em meio ágar sangue as quais foram transferidas para caldo $\mathrm{BHI}$ e após o crescimento, foi feito o teste antimicrobiano pela técnica de difusão em discos, usando os seguintes antibióticos: Ampicilina, Cefalexina, Gentamicina, Penicilina G e Oxacilina. Foram testadas também três concentrações de extrato hidroalcoólico de L. ferrea (extrato bruto, extrato $70 \%(\mathrm{v} / \mathrm{v})$ e extrato $50 \%(\mathrm{v} / \mathrm{v})$ ). Os microorganismos isolados apresentaram alta resistência a ampicilina, penicilina $G$ e oxacilina, apresentando resistência de 88,83 e $77 \%$, respectivamente. O extrato bruto apresentou uma eficiência de $61,1 \%$ na inibição dos micro-organismos em teste. O extrato hidroalcoólico bruto da casca de L. ferrea tem potencial como antimicrobiano natural contra micro-organismos causadores de mastite caprina.
\end{abstract}

Palavras-chave antibióticos; leite caprino; sensibilidade

\begin{abstract}
Dairy goat production is of great importance for the economy of the Northeast. Inadequate handling of goats causes a number of diseases that affect the production, among them, mastitis, an inflammation of the mammary glands, caused by a broad spectrum of microorganisms. The indiscriminate use of antibiotics in the treatment of mastitis causes the process of microbial resistance, which makes treating the disease. This study aims to test the antimicrobial activity of hydroalcoholic extract of the bark of Juca (Libidibia ferrea (Mart. ex Tul.) L.P.Queiroz) against microorganisms causing mastitis in goats. We isolated 18 bacterial strains grown on blood agar medium were transferred to $\mathrm{BHI}$ and after growth, antimicrobial testing was done by disc diffusion technique, using the following antibiotics: ampicillin, cephalexin, gentamicin, penicillin $\mathrm{G}$ and oxacillin. Three concentrations were tested extract of $L$. Ferrea (crude extract, extract $70 \%$ and extract $50 \%$ ). The results show that micro-organisms has high resistance to ampicillin, penicillin G, oxacillin, with resistor 88,83 and $77 \%$ respectively. The crude extract showed an efficiency of $61.1 \%$ in the inhibition of microorganisms. The results showed that the hydroalcoholic extract of the bark of $L$ ferrea iron as natural antimicrobial is effective against microorganisms causing mastitis goats.
\end{abstract}

Key Words: antibiotics; goat milk; sensibility 
Atividade antibacteriana da casca do jucá (Libidibia ferrea (Mart. Ex Tul.) L. P. Queiroz),

\section{INTRODUÇÃO}

A mastite, inflamação da glândula mamária, se destaca como uma das enfermidades mais comuns em rebanhos caprinos leiteiros. A incidência da mastite subclínica situa-se entre 5 e $30 \%$, sendo a mais predominante nesses animais, já a clínica é inferior a $5 \%$ (Contreras et al., 2007). Sua etiologia é ampla, sendo causada primordialmente por microorganismos (Anderson et al., 2004). Os principais gêneros bacterianos encontrados em casos de mastite em caprinos são: Staphylococcus spp., sendo os micro-organismos mais frequentemente isolados, Streptococcus spp., Corynebacterium spp., Pseudomonas sp., Mannheimia haemolytica. Algumas espécies de fungos também foram encontradas, contudo são menos frequentes (Contreras et al., 2007).

O uso indiscriminado de antibióticos no controle de micro-organismos causadores de doenças em raças de aptidão leiteira promove o aumento da resistência dos micro-organismos, dificultando o tratamento (Drescher et al., 2010).

$\mathrm{Na}$ atualidade, as propriedades terapêuticas dos produtos fitoterápicos começam a ganhar cada vez mais espaço no tratamento de doenças envolvendo micro-organismos em razão das muitas vantagens que oferecem como a possível diminuição nas reações adversas durante o tratamento e menor seleção de micro-organismos resistentes (Oliveira et al., 2010). Dentre as plantas já estudadas pela literatura, pode-se citar o Jucá (Libidibia ferrea (Mart. ex Tul.) L.P.Queiroz) que é uma árvore leguminosa nativa do Brasil, amplamente distribuída principalmente no Norte e Nordeste, essa planta tem sido usada na medicina popular para tratamento de afecções bronco-pulmonares, diabetes, reumatismo, câncer, distúrbios gastrintestinais, diarréia, inflamação e spp. Isolados do leite de cabras com mastite dor. No nordeste brasileiro, o pó da casca da Libidibia ferrea é utilizado para o tratamento de feridas cutâneas, pelo conhecimento empírico dos populares. Partindo desse conhecimento, 0 interesse nos estudos farmacológicos e biotecnológicos da casca da Libidbia ferrea é bastante promissor (Ximenes, 2004).

Considerando os transtornos econômicos aos caprinocultores causados pela mastite e a possibilidade do uso fitoterápico da L. ferrea, o presente trabalho visou a avaliação de um extrato fitoterápico a base de L. ferrea como potencial alternativa contra bactérias do gênero Staphylococcus que provocam mastite em caprinos.

\section{MATERIAL E MÉTODOS}

\section{MATERIAL BOTÂNICO}

As cascas de Libidibia ferrea (Mart. ex Tul.) L. P. Queiroz), foram coletadas em propriedade particular na zona rural do município de Mossoró-RN. Após a coleta, a amostra vegetal foi herborizada utilizando técnicas usuais em botânica, sendo incorporado ao acervo do Herbário MOSS da Universidade Federal Rural do SemiÁrido, com número de coleta 807 e registro MOSS 13795.

\section{ELABORAÇÃO DO EXTRATO}

Após a coleta, as cascas foram armazenadas a $40^{\circ} \mathrm{C}$ e posteriormente moídas em moinhos de navalha até uma granulometria de 20 mesh. Em seguida, as amostras foram pesadas e os extratos foram obtidos a partir de $10 \mathrm{~g}$ das cascas moídas com $100 \mathrm{~mL}$ de solução hidroalcoólica a $70 \%(\mathrm{v} / \mathrm{v})$ seguido de agitação a $200 \mathrm{rpm}$ em temperatura ambiente, por 3 horas (Duarte et al., 2004). O solvente foi retirado com ajuda de um rotaevaporador a uma temperatura de $55^{\circ} \mathrm{C}$, após essa etapa, $\mathrm{O}$ 
extrato foi filtrado com duas camadas de papel filtro de $2 \mathrm{~mm}$, em seguida, foram estocados em recipientes âmbar a uma temperatura de 0 a $20^{\circ} \mathrm{C}$ até seu uso (Pereira et al., 2006).

\section{MATERIAL MICROBIOLÓGICO}

A partir do leite de cabras, coletado de propriedade da região de Mossoró-RN, foi realizada a contagem de células somáticas utilizando 0 Aparelho Direct cell counter DeLavalDCC. Foram selecionadas 18 amostras que apresentaram uma contagem acima de $6 \times 105$ céls $/ \mathrm{mL}$. Em seguida as amostras foram enviadas, acondicionada em caixa de isopor com gelo reciclável, ao Laboratório de Inspeção de Produtos de Origem Animal (LIPOA).

As amostras de leite caprino foram semeadas em meio ágar sangue de carneiro em placas de Petri através de swabs e em seguida incubadas em estufa a $37^{\circ} \mathrm{C}$ por 24 horas, para crescimento de colônias de bactérias. Posteriormente foi realizado o isolamento e identificação dos microorganismos presentes nas amostras (Carter et al, 1986). Foram utilizadas as bactérias pertencentes ao gênero Staphylococcus spp. Posteriormente os micro-organismos foram semeados em tubos de ensaio contendo caldo Brain Heart Infusion $(\mathrm{BHI})$ por 24 horas a $37^{\circ} \mathrm{C}$ em estufa até atingirem turvação equivalente ao padrão 0,5 da escala Mac Farland (Bauer et al., 1966).

TESTE DA

ANTIMICROBIANA

Para comparação posterior com o potencial antimicrobiano do extrato de da casca do jucá foi utilizado a técnica de difusão em discos, descrita por Bauer et al. (1966), com algumas drogas antimicrobianas de uso farmacológico. $\mathrm{O}$ procedimento foi realizado em triplicata, em placas de petri contendo meio ágar Mueller Hinton. Utilizando swab estérilizados, pelo método de KirbyBauer, o inóculo bacteriano foi inoculada nas placas, com posterior inserção dos antibióticos beta lactâmicos: ampicilina $10 \mu \mathrm{g}$, cefalexina $30 \mu \mathrm{g}$, gentamicina 10 $\mu \mathrm{g}$, oxacilina1 $\mu \mathrm{g}$ e penicilina $\mathrm{G} 10 \mathrm{U}$. A interpretação dos dados foi feita de acordo com a tabela de halos padronizada pelo National Committee for Clinical Laboratory Standards (Nccls, 2003).

Para analisar 0 potencial antimicrobiano dos extratos de casca de jucá, foi utilizada técnica de difusão em discos. Foram adicionados em cada placa $20 \mu \mathrm{l}$ de extrato nos discos de papel filtro contendo as concentrações, em 3 diferentes concentrações (extrato bruto, extrato $70 \%$ e extrato $50 \%$ ), assim como o controle negativo (salina a $0,1 \%$ ) e controle positivo (antibióticos beta lactâmicos citados anteriormente).

Após 24 horas, incubadas em estufa bacteriológica a $37^{\circ} \mathrm{C}$, foi realizada a medição dos halos de inibição, utilizando um paquímetro.

\section{RESULTADOS E DISCUSSÃO}

A tabela 1 mostra o perfil de sensibilidade dos micro-organismos isolados, demonstrando resistência a ampicilina, penicilina $G$ e oxacilina, segundo a tabela de referência de testes de sensibilidade aos antimicrobianos por difusão em disco, segundo a ANVISA (Nccls, 2003). Já para cefalexina, os micro-organismos apresentam sensibilidade mediana e a gentamicina mostrou-se mais eficiente contra os micro-organismos isolados.

Resultado semelhante foi observado por Tomaz et al. (2013) que utilizaram extrato do fruto do Jucá e obtiveram inibição equivalente de gentamicina. $O$ resultado do presente experimento se 
Atividade antibacteriana da casca do jucá (Libidibia ferrea (Mart. Ex Tul.) L. P. Queiroz),

FRENTE A Staphylococcus spp. Isolados do leite de cabras com mastite

contrapõe aos apresentados por Schmidt et al., (2009) que observaram uma alta resistência de Streptococcus sp. a gentamicina $(75 \%)$, e baixa a oxacilina (25\%). Estudos realizados por Mendes (2013) demonstraram a resistência de Staphylococcus aureus a metacilina e vancomicina, evidenciando a alta taxa de resistência a uma grande variedade de antibióticos como: ampicilina, cefalexina, gentamicina, oxacilina e penicilina $\mathrm{G}$.



O alvo de atuação dos antibióticos $\beta$-lactâmicos são as chamadas proteínas ligadoras de penicilina (PBP), que são proteínas de membrana diretamente envolvidas na biossíntese da parede celular bacteriana (Boyle-vavra et al., 2003). Os $\beta$-lactâmicos, que interagem com as PBP, impedem a formação completa da camada de peptideoglicano da parede celular, provocando a morte bacteriana. As bactérias resistentes possuem o gene mecA, que produz uma proteína denominada PBP2a que funciona como uma substituta a PBP, proporcionando a resistência dos microorganismos.

Dentre as alternativas para a diminuição do uso descontrolado de antibióticos, surge a pesquisa dos extratos naturais com capacidade antimicrobiana e o extrato de L. ferrea avaliado no presente estudo se mostrou eficiente no combate aos microorganismos isolados.

A tabela 2 demonstra os valores em porcentagem da inibição dos microorganimos isolados. $O$ extrato bruto apresentou uma média de tamanho de halos três vezes maior, possuindo picos maiores de inibição, isso indica uma melhor atividade microbiana do extrato bruto. O extrato de L. ferrea possui a presença de flavonóides que confere características anti-inflmatórias ao extrato taninos conferindo ação antiséptica e cicatrizante, cumarinas, responsáveis pela ação antibacteriana e antifúngica.

Rodrigues et al. (2011) obtiveram bons resultados na avaliação antibacteriana contra bactérias do gênero Staphylococcus, utilizando extrato etanólico bruto de caule e sementes de Senna obtusifolia, com cerca de $30 \%$ de inibição e crescimento, assim como a atividade de antimicrobiana de Stryphnodendron adstringens (Mart.) foi comprovada por estudos de Hasenack et al., (2008).

O extrato a $50 \%$ teve resultado semelhante a Cavalheiro e colaboradores (2009), que não encontrou atividade antimicrobiana no extrato aquoso a partir de sementes trituradas de L. ferrea.

Tanto o extrato bruto, quanto o extrato a $70 \%$ obtiveram uma boa porcentagem de inibição (tabela 2), corroborando com a média dos halos obtidos por Pereira et al. (2006) que obtiveram uma média de $(7 \mathrm{~mm})$ com picos de $17 \mathrm{~mm}$ ao utilizarem extrato da casca de Punica granatum contra linhagens de Staphylococcus aureus e Escherichia coli, como também Zuque et al. (2004) obtiveram halo de inibição de 9 $\mathrm{mm}$ contra S. aureus a partir de extrato etanólico de Couepia grandiflora e halos de $19 \mathrm{~mm}$ contra Pseudomonas aeroginosa. Esses resultados se contrapõe aos encontrados por Kahn \& Omoloso (2002) que utilizando extrato etanólico de Harpullia petiolaris obtiveram uma média de halos de inibição de $14 \mathrm{~mm}$ contra $\mathrm{S}$. aureus, assim como o Hofmann Jr e colaboradores (2005) que obtiveram 
média dos halos de $17 \mathrm{~mm}$ utilizando extrato dos ramos de llex paraguariensis.

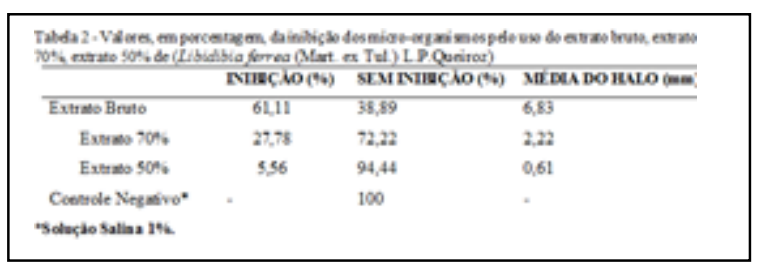

O presente trabalho obteve bons resultados na inibição de $S$. aureus, um dos principais organismos causadores de mastite em pequenos ruminantes, refutando trabalhos de Prabuseenivasan et al., (2006) e Tintino et al., (2009) que também utilizaram extratos naturais e não obtiveram inibição de $S$. aureus, confirmando a eficácia do presente estudo.

\section{CONCLUSÃO}

A obtenção de uma boa inibição dos micro-organismos contaminantes de leite de caprino, através do uso do extrato hidroalcoolico bruto da Libidibia ferrea (Mart. ex Tul.) L. P. Queiroz), confere a este um potencial natural antimicrobiano contra micro-organismos causadores de Mastite.

\section{REFERÊNCIAS}

ANDERSON, D.E.; HULL, B.H.; PUGH, D.G. Enfermidades da glândula mamária. In: PUGH, D.G. Clínica de ovinos e caprinos. São Paulo: Roca, p. 379-399, 2004.

BAUER, A.W.; KIRBY, W. M. M.; SHERRIS, J. C. et al. Antibiotic susceptibility testing by a standardized single disk method. American Journal of Clinical Pathology, v.45, p.493-496, 1966.

BOYLE-VAVRA, S.; YIN, S.; CHALLAPALLI, M.; DAUM R. Transcriptional Induction of the Penicillin-Binding Protein 2 Gene in Staphylococcus aureus by Cell Wall- Active Antibiotics Oxacillin and Vancomycin. Antimicrob Agent Chemother, v. 47, p. 1028-1036, 2003.
CARTER, G. R.; CLAUS, W.; RIKIHISA, Y. Essencials of veterinary bacteriology and mycology. 3.ed. Philadelphia: Lea \& Febiger, p. 261, 1986.

CAVALHEIRO, M. G.; FARIAS, D. F.; FERNANDES, G. S. et al. Atividades biológicas e enzimáticas do extrato aquoso de sementes de Caesalpinia ferrea Mart., Leguminosae. Revista Brasileira de Farmacognosia, v. 19, p. 586-591, 2009.

CONTRERAS A., SIERRA D., SÁNCHEZ A. et al. Mastitis in small ruminants. Small Rumin Research. v. 68, p.145-153, 2007.

DRESCHER, G.; MATTIELLO, S. P.; PEIXOTO, R. M. et al. Caracterização bioquímica e perfil de sensibilidade aos antimicrobianos de agentes bacterianos isolados de mastite subclínica ovina na região do oeste de Santa Catarina. Ciência Animal Brasileira, v. 11, p. 188-193, 2010.

DUARTE, M.C.T; FIGUEIRA G.M.; PEREIRA, B. et al. Atividade antimicrobiana de extratos hidroalcólicos de espécies da coleção de plantas medicinais CPQBA/UNICAMP. Revista Brasileira de Farmacognosia, v. 14, supl. 01, p. 06-08, 2004.

HASENACK, B. S.; SICHINELLI, J.M.; GARCIA, A.F. et al. Atividade Antibacteriana do Extrato Barbatimão sobre Cepas de Staphylococcus Aureus Isoladas de Secreções de Feridas Crônicas de Pacientes Ambulatoriais. UNOPAR Científica Ciências. Biológicas e Saúde, v. 10, n. 1, p. 13-18, 2008.

HOFMANN JR, A. E.; De BIASI, B.; GRAZZIOTIN, N. A.; Atividade antimicrobiana dos extratos de folhas e ramos da llex paraguariensis A. St.-Hil., Aquifoliaceae. Revista Brasileira de Farmacognosia, v. 19, p.582-585, 2009.

KHAN, M. R.; OMOLOSO, A. D.; Antibacterial and antifugal activity of Harpullia petiolaris. Fitoterapia, v.73, p. 331-335, 2002.

MENDES, D. C. A. M. Evolução da resistência aos antibióticos $\beta$-lactâmicos em Staphylococcus aureus. 2013. 69p. Monografia (Faculdade de Ciências da Saúde), Universidade Fernando Pessoa, Porto.

NATIONAL COMMITTEE FOR CLINICAL LABORATORY STANDARDS-NCCLS.

Performance standards for antimicrobial disk susceptibility tests for bacteria that grow aerobically. 8th.ed. Wayne: NCCLS, 2003. (NCCLS document M2-A8) 2003.

OLIVEIRA, A.F.; BATISTA, J.S.; PAIVA, E.S. et al. Avaliação da atividade cicatrizante do jucá (Caesalpinia ferrea Mart. ex Tul. var. ferrea) em 
Atividade antibacteriana da casca do jucá (Libidibia ferrea (Mart. Ex Tul.) L. P. Queiroz), FRENTE A Staphylococcus spp. Isolados do leite de cabras com mastite lesões cutâneas de caprinos. Revista Brasileira de Plantas Medicinais. v.12, n.3, p.302-310, 2010.

PRABUSEENIVASAN, S.; JAYAKUMAR, M.; IGNACIUTHU, S. In vitro antibacterial activity of some plant essential oils. BMC Complementaty Alternative Medicine. v.6, p.39, 2006.

PEREIRA, M.S.V.; RODRIGUES, O.G.; FEIJÓ, F.M.C. et al. Atividade antimicrobiana de extratos de plantas no Semi-Árido Paraibano. Agropecuária Científica no Semi-árido. v.2, 2006.

RODRIGUES, A.C.F.; COSTA, J.F.; SILVA, F.R.V. et al. ATIVIDADE ANTIBACTERIANA, ANTIOXIDANTE E TOXICIDADE DO EXTRATO ETANÓLICO DE Senna obtusifolia. Revista Semente, v.6, p. 250-257, 2011.

SCHMIDT, V; PINTO, A. T; SCHNEIDER, R. N; et al. Caracterização da mastite subclínica em caprinos produzidos em sistema orgânico no Rio Grande do Sul. Pesquisa Veterinária Brasileira. v. 29, p.774-778, 2009.

TINTINO, S.R.; GUEDES, G.M.M.; CUNHA, F.A.B. et al. Avaliação in vitro da Atividade Antimicrobiana e Moduladora dos Extratos Etanólico e Hexânico de Bulbo de Costus arabicus. Bioscience Jornal. v. 29, n. 3, p. 732738, 2013.

TOMAZ, K.L.R.; ABRANTES, M.R.; ROCHA, M.O.C. et al. Atividade antimicrobiana do extrato alcoólico do fruto da Caesalpinia ferrea Mart. frente a bactérias causadoras de mastite bovina. Acta Scientia Veterinariae, v.41, p. 1143, 2013.

XIMENES, N.C.A. Purificação e Caracterização da Lectina da Vagem da Caesalpinia ferrea (CfePL): aplicação biológica. 2004. 53p. Dissertação (Mestrado em Bioquímica Departamento de Bioquímica) - Centro de Ciências Biológicas, Universidade Federal do Pernambuco, Recife.

ZUQUE, A. L. F.; WATANABE, E. S.; FERREIRA, A. M. T.; et al. Avaliação da atividade antioxidante, antimicrobiana e citotóxica de Couepia grandiflora Benth. (Chrysobalanaceae). Revista Brasileira de Farmacognosia, v. 14, p. 129-136, 2004. 